\title{
Intersegmental Coordination of Limb Movements during Locomotion: Mathematical Models Predict Circuits That Drive Swimmeret Beating
}

\author{
Frances K. Skinner ${ }^{1}$ and Brian Mulloney ${ }^{2}$ \\ ${ }_{1}^{1}$ Playfair Neuroscience Unit, The Toronto Hospital Research Institute, and Institute of Biomedical Engineering, University \\ of Toronto, Toronto, Ontario M5T 2S8, Canada, and 2Section of Neurobiology, Physiology, and Behavior, University of \\ California, Davis, CA 95616-8755
}

Normal locomotion in arthropods and vertebrates is a complex behavior, and the neural mechanisms that coordinate their limbs during locomotion at different speeds are unknown. The neural modules that drive cyclic movements of swimmerets respond to changes in excitation by changing the period of the motor pattern. As period changes, however, both intersegmental phase differences and the relative durations of bursts of impulses in different sets of motor neurons are preserved. To investigate these phenomena, we constructed a cellular model of the local pattern-generating circuit that drives each swimmeret. We then constructed alternative intersegmental circuits that might coordinate these local circuits. The structures of both the model of the local circuit and the alternative models of the coordinating circuit were based on and constrained by previous experimental results on pattern-generating neurons and coordinating interneurons.
To evaluate the relative merits of these alternatives, we compared their dynamics with the performance of the real circuit when the level of excitation was changed. Many of the alternative coordinating circuits failed. One coordinating circuit, however, did effectively match the performance of the real system as period changed from 1 to $3.2 \mathrm{~Hz}$. With this coordinating circuit, both the intersegmental phase differences and the relative durations of activity within each of the local modules fell within the ranges characteristic of the normal motor pattern and did not change significantly as period changed. These results predict a mechanism of coordination and a pattern of intersegmental connections in the CNS that is amenable to experimental test.

Key words: pattern generation; coordination; interneuron; constant phase; excitation; mathematical model; frequency changes
Effective locomotion using limbs located on different segments of an animal's body requires that the nervous system coordinate firing of different populations of motor neurons that innervate these different limbs. Limbs on different segments are normally coordinated so that they move through repeated cycles of protraction and retraction with a particular phase relative to their neighbors, a phase that is preserved when the periods of these movements change. In both terrestrial vertebrates and arthropods, the CNS can produce the fully coordinated motor output needed to drive these movements without any sensory input, but how this performance is accomplished is not understood.

Swimmerets are paired limbs found on four or five abdominal segments that propel a crayfish through the water when it swims forward. When they are active, the left and right swimmerets of each segment move in phase through cycles of power strokes and return strokes, and swimmerets on neighboring segments differ in phase by $\sim 25 \%$. The most posterior pair starts each cycle of movements. These periodic movements are driven by a complex motor pattern (Fig. 1) that can be produced by the isolated

Received Nov. 12, 1997; revised Feb. 20, 1998; accepted Feb 25, 1998.

This work was supported by a University of California president's fellowship to F.K.S. and by National Science Foundation Grant BNS 95-14889 to B.M. We thank Nancy Kopell for provocative discussions, Karen Sigvardt, Ken Britten, Hisaaki Namba, and Wendy M. Hall for reading this manuscript critically, and Wendy M. Hall for data analysis and preparing illustrations.

Correspondence should be addressed to Dr. Frances K. Skinner, Playfair Neuroscience Unit, The Toronto Hospital, Western Division, 399 Bathurst Street, MP12-303, Toronto, Ontario M5T 2S8, Canada.

Copyright (ㄷ) 1998 Society for Neuroscience $\quad 0270-6474 / 98 / 183831-12 \$ 05.00 / 0$ abdominal nervous system (Hughes and Wiersma, 1960; Ikeda and Wiersma, 1964). When the system is uniformly excited, neither intersegmental phases nor relative durations of bursts of impulses in motor neurons change significantly as period changes (Mulloney et al., 1993; Braun and Mulloney, 1995; Mulloney, 1997). Moreover, any neighboring pair of segments, isolated from the rest, can produce normally coordinated swimmeret activity (Paul and Mulloney, 1986). How does the nervous system do it?

In a previous paper (Skinner et al., 1997), we put aside the cellular details of the swimmeret system to consider it as a chain of four segmental oscillators that were coupled bidirectionally to their nearest neighbors. Given certain values of its parameters, this phase-coupled oscillator (PCO) model could reproduce the changes in period and intersegmental phase caused by uniform and nonuniform excitation in the system (Braun and Mulloney, 1995). These simulations predicted that (1) excitation must affect the properties of each segmental oscillator; (2) coupling between segments is asymmetric, but ascending and descending coupling are about equally strong, and either ascending or descending coupling alone can cause a phase difference of $\sim 25 \%$, with posterior leading; and (3) changes in intersegmental coupling do not affect period significantly. What do these properties mean in neural terms, and how do they emerge from the cellular components and synaptic organization of the swimmeret system?

In this paper, we introduce a cellular model of the local pattern-generating module that incorporates properties of its known components. We then construct alternative circuits that intersegmental coordinating interneurons might make to link 


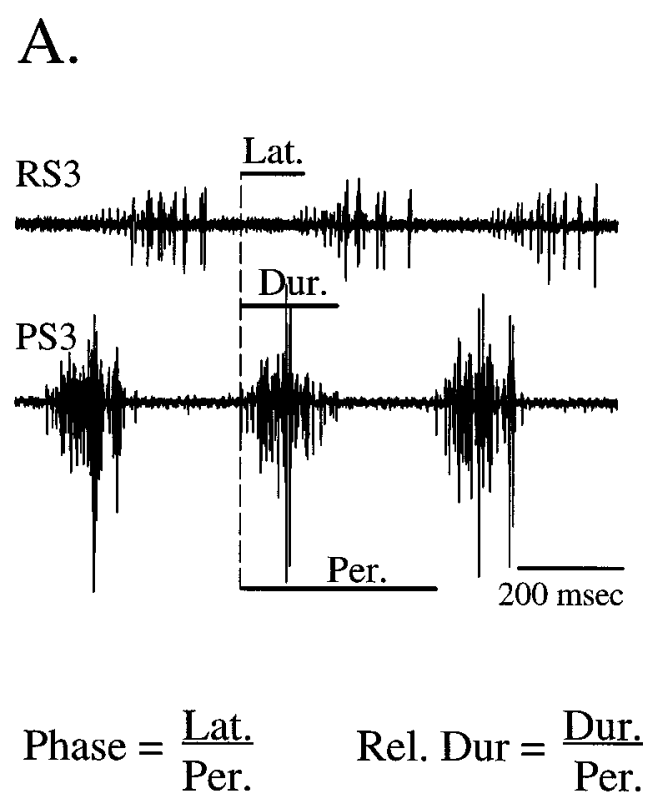

\section{B.}
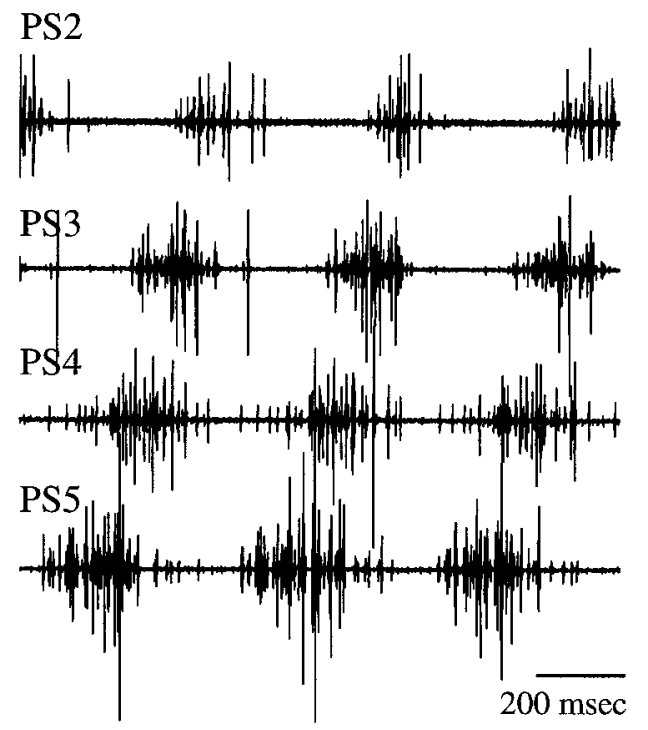

Figure 1. A, Motor pattern that drives one swimmeret when the swimmeret system is active. Bursts of impulses occur alternately in axons of power stroke (PS3) and return stroke (RS3) motor neurons. B, Coordinated output to four swimmerets on different segments. PS2-PS5, Recordings from the power stroke branch of the swimmeret nerves in abdominal segments 2-5. Lat., Latency; Dur., duration; Per., period; Rel. Dur., relative duration.

neighboring modules and compare the dynamics of these alternatives with the performance of the swimmeret system itself. From this comparison, one circuit emerges with dynamics that are similar to those of the real system. These results illustrate in cellular terms the asymmetry required by the PCO model, illustrate mechanisms that cause complex properties to emerge, and predict a pattern of intersegmental connections in the CNS.

\section{MATERIALS AND METHODS}

\section{Physiological experiments}

Crayfish, Pacifastacus leniusculus, were obtained from commercial suppliers and maintained in aerated tanks of tap water at $12-15^{\circ} \mathrm{C}$. Crayfish were anesthetized on ice before dissection. The recording methods have been described in detail elsewhere (Sherff and Mulloney, 1996; Mulloney, 1997). The level of excitation was controlled by superfusing preparations with different concentrations of carbachol (Mulloney, 1997).

Each cycle of activity in the swimmeret motor pattern is defined as beginning with a burst of impulses in power stroke motor neurons in the most posterior ganglion, A5 (Mulloney and Hall, 1987). The definitions of bursts of impulses, their periods, durations, and phases are illustrated in Figure 1. Relative durations are defined as the duration of each burst divided by the period of the cycle in which it occurred (Fig. 1). To extend these terms to computations of nonspiking neurons, we defined the "burst" of each nonspiking cell as starting when its membrane potential rose above its threshold for transmitter release and lasting as long as its potential remained above this threshold (see below).

\section{Computational procedures}

Local interneurons and graded synapses. We modeled each local interneuron as a cell with a single compartment (Perkel and Mulloney, 1978; Edwards and Mulloney, 1984, 1987; Mulloney and Perkel, 1988). Each cell was constructed with two voltage-gated currents, an inward " $\mathrm{Ca}$ " current that activated rapidly relative to an outward "K" current that activated more slowly, and as many synaptic currents as were needed to construct the circuit under consideration (Skinner et al., 1994; Sharp et al., 1996). The first-order ordinary differential equations that describe these cells and their currents (Morris and Lecar, 1981) have been used before to study neurons in synaptic circuits (Skinner et al., 1994; Sharp et al., 1996). The equations that describe each nonspiking local interneuron and its synapses are:

$$
\begin{aligned}
& C \frac{d V}{d t}=I_{\mathrm{ext}}-\left[g_{\mathrm{L}}\left(V-V_{\mathrm{L}}\right)+\right. g_{\mathrm{Ca}} M_{\infty}\left(V-V_{\mathrm{Ca}}\right) \\
&\left.+g_{\mathrm{K}} N\left(V-V_{\mathrm{K}}\right)+g_{\mathrm{syn}} S\left(V-V_{\mathrm{syn}}\right)\right] ; \\
& \frac{d N}{d t}=\lambda_{\mathrm{N}}\left(N_{\infty}-N\right) ; \\
&\left(1-S_{\infty}\right) \tau_{\mathrm{s}} \frac{d S}{d t}=\left(S_{\infty}-S\right),
\end{aligned}
$$

where

$$
\begin{gathered}
M_{\infty}=\frac{1}{2}\left[1+\tanh \left(\frac{V-V_{1}}{V_{2}}\right)\right] ; \\
N_{\infty}=\frac{1}{2}\left[1+\tanh \left(\frac{V-V_{3}}{V_{4}}\right)\right] ; \\
\lambda_{N}=\phi_{N} \cosh \left(\frac{V-V_{3}}{2 V_{4}}\right) ; \\
S_{\infty}=\tanh \left(\left(V_{\text {pre }}-V_{\text {thresh }}\right) / V_{\text {slope }}\right), \quad \text { if } V_{\text {pre }}>V_{\text {thresh }} ; \text { otherwise } 0,
\end{gathered}
$$

where $C$ is the capacitance of the cell; $V$ is its membrane voltage; $t$ is time; $I_{\text {ext }}$ is any imposed current; $g_{\mathrm{L}}, g_{\mathrm{Ca}}$, and $g_{\mathrm{K}}$ are the maximal leak, calcium, and potassium conductances, respectively; $V_{\mathrm{L}}, V_{\mathrm{Ca}}$, and $V_{\mathrm{K}}$ are the reversal potentials of the leak, calcium, and potassium currents, respectively; $M_{\infty}$ and $N_{\infty}$ are the fractions of open calcium and potassium channels at steady state, respectively; $N$ is the fraction of potassium channels that are actually open; $\lambda_{N}$ is the rate constant of potassium channel opening, and $\phi_{N}$ is the minimum of $\lambda_{N} ; V_{1}$ and $V_{3}$ are the voltages at which half the channels are open at steady state; and $V_{2}$ and $V_{4}$ are voltages with reciprocals that are the slopes of the voltage dependence of $\mathrm{Ca}$ and $\mathrm{K}$ channel opening at steady state.

Each synapse onto the cell controls a synaptic current that is a term in Equation $1 . g_{\text {syn }}$ is the maximal synaptic conductance; $S$ is the instantaneous synaptic activation; $S_{\infty}$ is the steady-state synaptic activation; $V_{\text {syn }}$ is the reversal potential of the synaptic current; $V_{\text {pre }}$ and $V_{\text {thresh }}$ are the membrane potential and the synaptic threshold potentials of the presynaptic cell, respectively; and $V_{\text {slope }}$ is the voltage with a reciprocal that is the slope of the voltage dependence of synaptic conductance. The term 
$\left(1-S_{\infty}\right) \tau_{S}$ occurs in Equation 3 because the time constant, $\tau_{S}$, refers only to decay of synaptic current, not to a combination of rise times and decay.

To calibrate the model, we used measured membrane time constants, input resistances, and membrane potentials of swimmeret motor neurons (Sherff and Mulloney, 1997) and local interneurons (B. Mulloney, unpublished results).

Intersegmental synaptic connections. The local circuits within neighboring modules are coupled by a separate circuit of spiking interneurons that conduct bursts of impulses between ganglia (Wiersma and Hughes, 1961; Stein, 1971). Pairs of these coordinating interneurons originate in each ganglion and fire in phase with the modules of the ganglion (Paul and Mulloney, 1986), but their targets in neighboring modules are unknown. To connect cells in neighboring modules, we used a "spike-mediated transmission (SMT) threshold" method to simulate these intersegmental interneurons. Accordingly, as long as the membrane potential of a cell that drives an intersegmental interneuron in one module is above a specified threshold, "spikes" of a specified duration are conducted to the target cells at a specified frequency. Each of these spikes causes a new current in the target neuron, $I_{\text {inter.syn }}$, which becomes an additional term in Equation 1 for the target cell. This current is described by:

$$
I_{\text {inter.syn }}=g_{\text {inter.syn }} r\left(V-V_{\text {syn }}\right),
$$

where $r$ is the synaptic activation, and $g_{\text {inter.syn }}$ is the maximal intersegmental synaptic conductance. If the presynaptic neuron is below the SMT threshold, $r$ is zero; otherwise it follows a first-order kinetic model of receptor binding (Destexhe et al., 1994):

During a spike $t_{0}<t<t_{1}$,

$$
r=r_{\infty}\left[1-\exp \left(\frac{-\left(t-t_{0}\right)}{\tau_{\mathrm{r}}}\right)\right] .
$$

During an interspike interval $\left(t>t_{1}\right)$,

$$
r=r_{1} \exp \left(-\beta\left(t-t_{1}\right)\right)
$$

where

$$
\begin{gathered}
r_{1}=r_{\infty}\left[1-\exp \left(\frac{-\left(t_{1}-t_{0}\right)}{\tau_{r}}\right)\right] ; \\
\tau_{r}=1 /(\alpha T+\beta) ; \\
r_{\infty}=\alpha T /(\alpha T+\beta) .
\end{gathered}
$$

$t_{0}$ is the time when each spike begins; $t_{1}$ is the time when it ends; $\alpha$ and $\beta$ are the forward and backward rate constants for transmitter binding, respectively; and $T$ is the transmitter concentration.

These differential equations were integrated numerically on a Pentium computer with Linux using LSODE (Hindmarsh, 1983), a doubleprecision subroutine capable of handling stiff systems of ordinary differential equations. Except where otherwise specified, the values of parameters used in these computations are given in Table 4. Multistable behavior was observed in several cases. However, for all runs performed, different sets of initial conditions were used to uncover different stable states and to approximate how large the stability region was.

\section{RESULTS}

Each swimmeret in crayfish is driven by its own patterngenerating module (Murchison et al., 1993) that includes power stroke and return stroke motor neurons, sensory neurons from the swimmeret, and a set of unilateral nonspiking local interneurons that generate the alternating drive to the different motor neurons (Paul and Mulloney, 1985a,b; Killian and Page, 1992a,b; Sherff and Mulloney, 1997). Each segmental ganglion has two of these modules that drive the alternating power and return stroke movements of the two swimmerets of that segment. There are no significant differences in the intrinsic periods of modules in dif-

\begin{tabular}{|c|c|c|c|c|}
\hline Name & $n$ & Soma position & $\begin{array}{l}\text { Depolarized } \\
\text { phase }\end{array}$ & $\begin{array}{l}\text { Discrete } \\
\text { PSPs }\end{array}$ \\
\hline $1 \mathrm{~A}$ & 1 & Posterolateral & RS & IPSPs \\
\hline 1B & 1 & Posterolateral & $\mathrm{RS}$ & EPSPs \\
\hline $2 \mathrm{~A}$ & 2 & Anterolateral & PS & None \\
\hline
\end{tabular}
ferent segments (Mulloney, 1997). Within the crayfish nervous system, certain interneurons have been identified that contribute to the performance of the swimmeret system and must be considered in any attempt to construct a mechanistic explanation of that performance.

\section{Unilateral nonspiking local interneurons}

The core of the pattern-generating circuit within each module is the synaptic organization of the nonspiking local interneurons that drive the motor neurons (Heitler and Pearson, 1980; Paul and Mulloney, 1985a,b; Sherff and Mulloney, 1996). The present evidence indicates that three types of unilateral nonspiking local interneurons that occur in each module are required for its normal operation (Table 1). These interneurons have unilateral structures; that is, their major processes are restricted to one lateral neuropil (Skinner, 1985). Perturbations of any of these interneurons resets the timing of ongoing swimmeret activity, and each interneuron can drive subpopulations of motor neurons effectively. Each of these interneurons also has distinctive connections within its own module. Other local interneurons also occur in each segment, but they do not appear to be necessary components of the local pattern-generating circuit (Paul and Mulloney, 1985a,b).

\section{A model of the local pattern-generating circuit}

A minimal local pattern-generating circuit (Fig. 2A) consistent with these data includes four nonspiking interneurons: two identical 2A interneurons that excite power stroke excitor (PSE) motor neurons, and two other interneurons, $1 \mathrm{~A}$ and $1 \mathrm{~B}$, with different synaptic input that excite return stroke excitor (RSE) motor neurons. Other local interneurons are omitted. The motor neurons export the activity of these pattern-generating neurons to the muscles of the swimmeret, but their own synaptic interactions do not play a major role in generating the fundamental alternation of power stroke and return stroke activity (Sherff and Mulloney, 1996) and so were not included in these simulations. To compare the activity of the simulated circuit with the output of the real system, we assume in this paper that the PSE motor neurons fire whenever and as long as interneuron $2 \mathrm{~A}$ is depolarized, and that the RSE motor neurons fire whenever and as long as interneurons $1 \mathrm{~A}$ or $1 \mathrm{~B}$ are depolarized.

These are nonspiking neurons, so they are particularly well described by equations of the Morris-Lecar type. To help the reader distinguish between interneurons found in crayfish and our models of these interneurons, we will refer to real interneurons in regular type but will refer to models as cells named in bold type. Each interneuron was modeled as a single-compartment cell that had one inward voltage-gated current, one outward voltagegated current, a leak current, and as many synaptic currents as needed (see Materials and Methods). Because the $1 \mathrm{~A}$ and $1 \mathrm{~B}$ interneurons differ in the PSPs they receive during swimmeret activity (Table 1), we modeled each of them separately as cells $\mathbf{1 A}$ and $1 B$. Because the known properties of the $2 \mathrm{~A}$ interneurons are the same, we combined them and their connections into one cell called 2A.

In our simulation of this circuit (Fig. $2 A$ ), the $\mathbf{2 A}$ cell and $\mathbf{1 A}$ and $\mathbf{1 B}$ cells are functional antagonists that reciprocally inhibit one another. Individual graded synapses between these neurons 

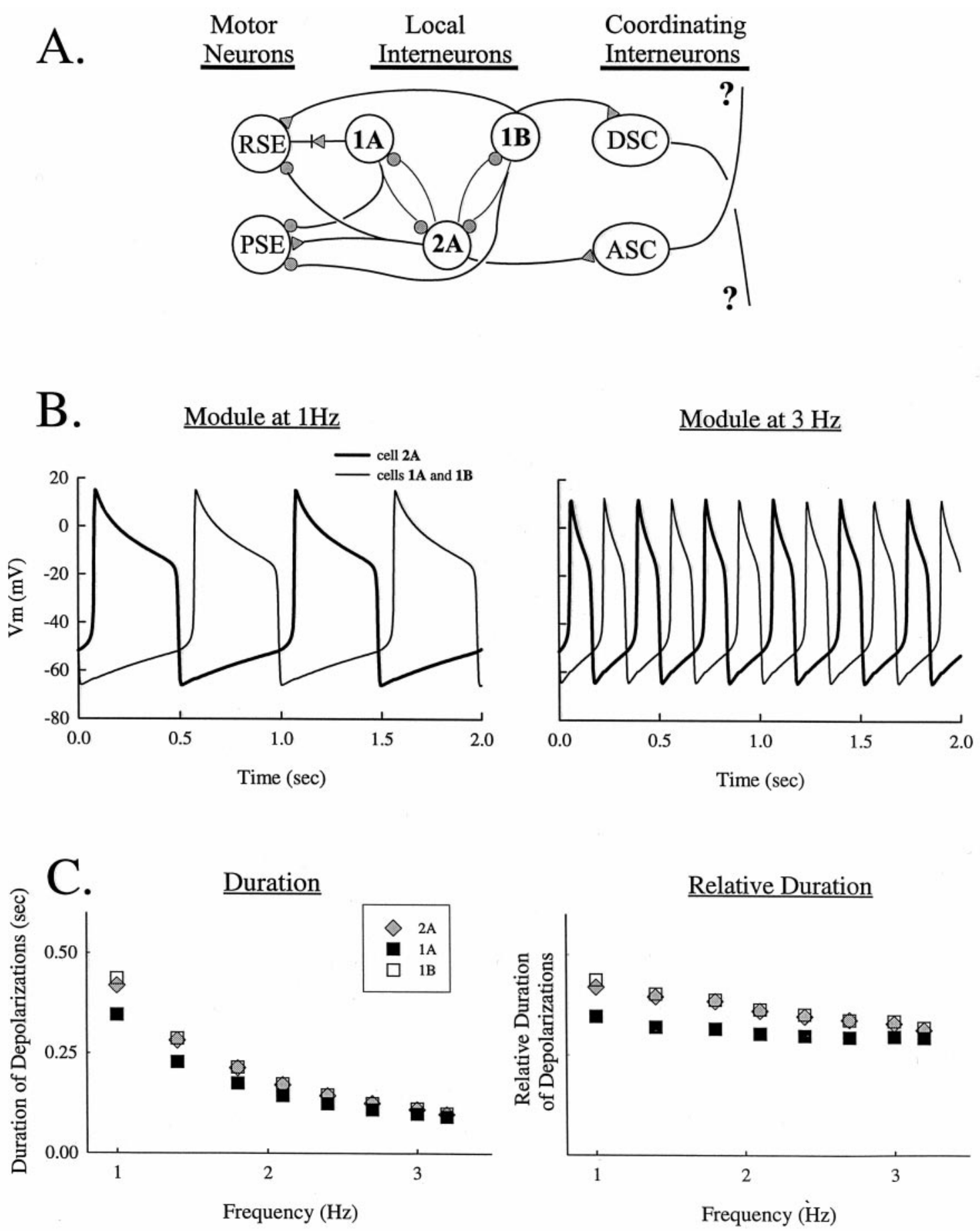

Figure 2. A, Diagram of the proposed model of the pattern-generating circuit formed by nonspiking local interneurons within each module and the connections these interneurons make with swimmeret motor neurons and coordinating interneurons. 2A, 1A, 1B, Individual local cells. PSE, RSE, Power stroke excitor and return stroke excitor motor neurons, respectively; ASC, DSC, ascending and descending coordinating interneurons, respectively. Gray circles, Graded chemical inhibitory synapses; gray triangles, graded excitatory chemical synapses; diode symbol, rectifying electrical synapse (Paul and Mulloney, 1985a). B, Two series of computed oscillations of membrane potentials in $\mathbf{2 A}$ and $\mathbf{1 A}$ cells at $1 \mathrm{~Hz}\left(\phi_{N}=0.003 \mathrm{msec}{ }^{-1}\right)$ and $3 \mathrm{~Hz}\left(\phi_{N}=0.010\right.$ $\left.\mathrm{msec}^{-1}\right)$. $C$, Plots of durations and relative durations of computed oscillations in cells within the same module as functions of frequency.

were simulated as postsynaptic membrane conductances, the values of which are functions of the membrane potential of the presynaptic cell (Skinner et al., 1994). Individual cells did not oscillate on their own but required reciprocal inhibition to generate oscillations of membrane potential. The dynamics of this model resembled those of the real circuit in that the membrane potentials of each cell oscillated with the same period; depolarizations of $\mathbf{2 A}$ alternated with depolarizations of $\mathbf{1 A}$ and $\mathbf{1 B}$ (Fig. $2 B$ ), and each of these depolarizations lasted approximately half the period of the oscillation (Fig. 2C). These features did not change significantly despite changes in the period of these oscillations (see below). 


\begin{tabular}{|c|c|c|c|c|c|c|c|}
\hline Tract $^{a}$ & $\mathrm{Name}^{b}$ & $n$ & Home Ganglion & Region $^{c}$ & Direction & Phase & Size \\
\hline \multirow[t]{3}{*}{ Medial ascending } & $A 44$ & 1 & A4 & 78 & Ascending & Late PS & Medium \\
\hline & $A 45$ & 1 & A5 & 78 & Ascending & Late PS & Medium \\
\hline & Anon & 1 & $?$ & 78 & Ascending & PS & Small \\
\hline \multirow{2}{*}{ Lateral ascending } & $A 31$ & 1 & A4 & 81 & Ascending & Late PS & Medium \\
\hline & $A 35$ & 1 & A5 & 81 & Ascending & Late PS & Medium \\
\hline Medial descending & Anon & $2(?)$ & $?$ & 76 (near 78) & Descending & $\mathrm{RS}$ & Small \\
\hline
\end{tabular}

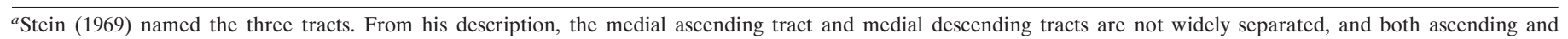
descending impulse traffic could sometimes be recorded with the same suction electrode.

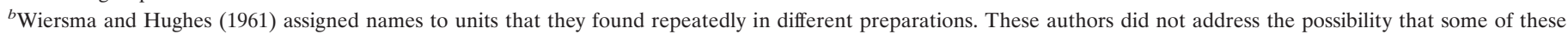
units were axons of homologous neurons that originated serially in each ganglion.

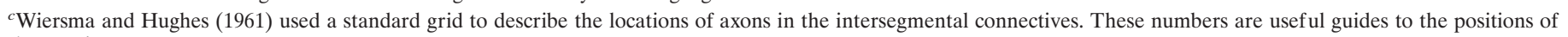
these units.

Anon, Tract not named; ?, unknown or uncertain.

\section{Intersegmental coordinating neurons}

These interneurons fire in phase with either power stroke (PS) or return stroke (RS) activity in their home module and project axons from one ganglion to the next (Table 2). In two pioneering studies, Wiersma and Hughes (1961) and Stein (1969, 1971) described three types of "fibers" in the interganglionic connectives that normally carried phasic information between ganglia whenever the swimmerets were active. Although these coordinating neurons do project farther than the next ganglion (Table 2), information from more distant ganglia is not required to produce normal coordination (Paul and Mulloney, 1986). From this evidence, a minimal set of intersegmental coordinating neurons that couple two neighboring modules would be two ascending neurons that fire in power stroke phase, and one descending neuron that fired in return stroke phase. In the models described here, simulated coordinating axons connected only to targets in neighboring segments.

In this series of simulations, we did not explicitly simulate each coordinating interneuron (see Materials and Methods) but instead assumed that coordinating interneurons that fire during bursts of impulses in PSE motor neurons are driven by synaptic input from cell $\mathbf{2 A}$, and those that fire with RSE motor neurons are driven by synaptic input from cells $\mathbf{1 A}$ or $\mathbf{1 B}$ (Fig. $2 A$ ). To simulate their firing, each ascending and descending unit generated periodic impulses of specified duration and frequency as long as the local cell that drove it was depolarized above a specified threshold. We simulated the postsynaptic consequences of these impulses as synaptic currents in putative target neurons in neighboring modules (see Materials and Methods). Each of these events triggered a change in a synaptic conductance in the target neuron.

\section{Possible structures of the circuit that coordinates neighboring modules}

There are at least two parallel ascending axons that conduct information to unknown targets in the next anterior module (Table 2). These axons fire bursts of impulses late in the PS phase of the cycle of their home ganglion, when the $2 \mathrm{~A}$ interneurons are depolarized. In our models, there were three possible target neurons, and each of the connections could be excitatory or inhibitory. To discover circuits made of these components that performed like the real system, we did a series of simulations of particular alternative circuits. Because normal coordination can be produced with any two neighboring ganglia (Paul and Mulloney, 1986), we made two models of the local pattern-generating circuit (Fig. $2 A$, local cells) with the same values for their parameters (see Table 4) to simulate the two swimmeret modules on one side of the abdomen. Because we were concerned with intersegmental coordination, not bilateral coordination, we constructed one local circuit for each segment.

The PCO model predicted that ascending connections alone should be able to produce stable phase differences of $\sim 25 \%$, so we began by considering only ascending connections. There are 12 possible circuits with two ascending connections to three possible targets that can be excitatory or inhibitory. Because in the model the intrinsic properties of $\mathbf{1 A}$ and $\mathbf{1 B}$ are the same, a circuit with an excitatory synapse from $\mathbf{2} \mathbf{A}_{n+1}$ to $\mathbf{1} \mathbf{A}_{n}$ and an inhibitory synapse from $\mathbf{2} \mathbf{A}_{n+1}$ to $\mathbf{2 A}_{n}$ would produce the same phase relationships as an excitatory synapse from $\mathbf{2 A}_{n+1}$ to $\mathbf{1 B}_{n}$ and an inhibitory synapse from $\mathbf{2} \mathbf{A}_{n+1}$ to $\mathbf{2 A}_{n}$ and so forth. This reduces the number of different possible circuits to 7 . Therefore, we constructed seven qualitatively different patterns of ascending connections between the two local circuits (Fig. 3) and explored the properties of each alternative through a $0.01-0.05 \mathrm{mS} / \mathrm{cm}^{2}$ range of synaptic conductances in their target cells (Table 3).

Within each module cells $\mathbf{1 A}$ and $\mathbf{1 B}$ are antiphase to cell $\mathbf{2 A}$, so one might expect that an "intermediate" phase of $25 \%$ would require the two ascending connections to "contradict" each other, that is, to be excitatory both to $\mathbf{2 A}$ and $\mathbf{1 A} / \mathbf{1 B}$, or inhibitory both to $\mathbf{2 A}$ and to $\mathbf{1 A} / \mathbf{1 B}$, or excitatory to $\mathbf{1 A}$ (or $\mathbf{1 B}$ ) but inhibitory to 1B (or 1A). These patterns occur in Figure 3, circuits 2, 3, and 5. However, Table 3 shows that only circuits 3 and 5 produced appropriate lags, and circuit 5 was much more robust. Therefore, the alternative that produced appropriate phase lags for the widest range of synaptic strengths had an excitatory synapse from $\mathbf{2 A}_{n+1}$ to $\mathbf{1} \mathbf{B}_{n}$ and an inhibitory synapse from $\mathbf{2} \mathbf{A}_{n+1}$ to $\mathbf{1} \mathbf{A}_{n}$ (Fig. 4). Because in each simulation the cellular properties of $\mathbf{1 A}$ and 1B were identical, this is equivalent to an excitatory synapse from $\mathbf{2 A}_{n+1}$ to $\mathbf{1} \mathbf{A}_{n}$ and an inhibitory synapse from $\mathbf{2 A}_{n+1}$ to $\mathbf{1 B}{ }_{n}$. We note that circuit 5 is consistent with the bursts of discrete PSPs recorded from these $1 \mathrm{~A}$ and $1 \mathrm{~B}$ interneurons during normal activity (Table 1).

There is also at least one descending axon that fires bursts of impulses during the RS phase in the cycle of its home ganglion, when the $1 \mathrm{~A}$ and $1 \mathrm{~B}$ interneurons are depolarized, and conducts this information to the next posterior module. The PCO model predicted that descending connections should also be able to produce stable phase differences of $\sim 25 \%$. However, with only one descending connection, it seemed unlikely that stable inter- 
$\underline{1}$

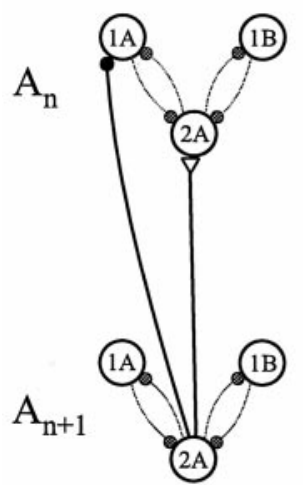

$\underline{2}$

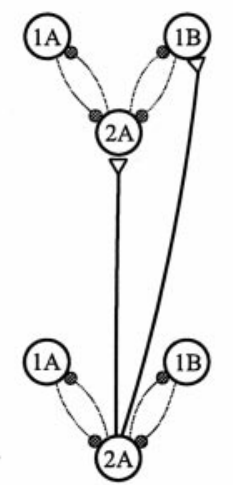

$\underline{3}$

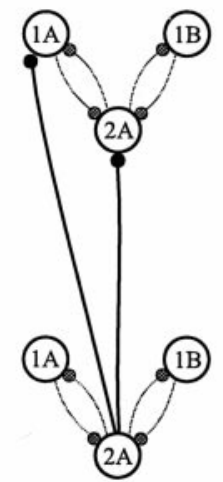

$\underline{4}$

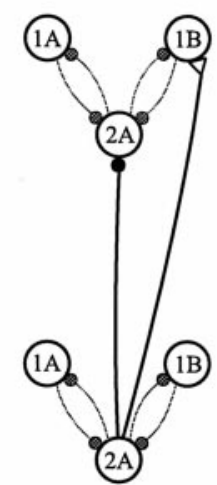

$\underline{5}$

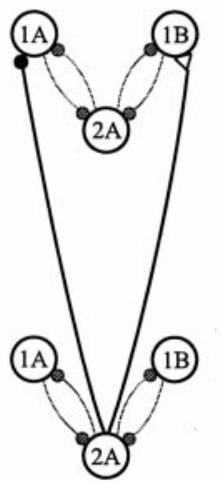

$\underline{6}$

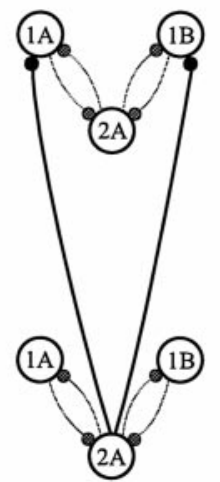

$\underline{7}$

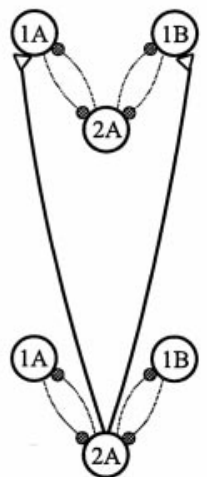

Figure 3. Diagrams of seven alternative circuits (1-7) that might be made by ascending coordinating interneurons with targets in the pattern-generating module of the next anterior ganglion. Each connection from segment $\mathrm{A}_{n+1}$ to segment $\mathrm{A}_{n}$ is driven by input from cell $2 \mathrm{~A}$ in the more posterior module (Fig. 2A).

\section{Table 3. Intersegmental phase lags of $2 \mathrm{~A}$ cells in anterior modules coupled by pairs of ascending intersegmental connections that form seven} alternative circuits (Fig. 3)

\begin{tabular}{|c|c|c|c|c|c|c|c|c|c|c|c|c|c|c|}
\hline \multirow[b]{3}{*}{$\begin{array}{l}\text { Conductances } \\
\left(\mathrm{mS} / \mathrm{cm}^{2}\right)\end{array}$} & \multicolumn{14}{|c|}{ Circuit } \\
\hline & \multicolumn{2}{|l|}{1} & \multicolumn{2}{|l|}{2} & \multicolumn{2}{|l|}{3} & \multicolumn{2}{|l|}{4} & \multicolumn{2}{|l|}{5} & \multicolumn{2}{|l|}{6} & \multicolumn{2}{|l|}{7} \\
\hline & $\begin{array}{l}\mathbf{2 A} \\
\nabla\end{array}$ & $\begin{array}{l}1 \mathrm{~A} \\
\mathbf{0}\end{array}$ & $\begin{array}{c}\mathbf{2 A} \\
\nabla\end{array}$ & $\begin{array}{c}\mathbf{1 B} \\
\nabla\end{array}$ & $\begin{array}{l}2 \mathrm{~A} \\
\bullet\end{array}$ & $\begin{array}{l}\mathbf{1 A} \\
0\end{array}$ & $\begin{array}{c}2 \mathrm{~A} \\
0\end{array}$ & $\begin{array}{l}\mathbf{1 B} \\
\nabla\end{array}$ & $\begin{array}{c}1 \mathrm{~A} \\
0\end{array}$ & $\begin{array}{l}\mathbf{1 B} \\
\nabla\end{array}$ & $\begin{array}{l}1 \mathrm{~A} \\
0\end{array}$ & $\begin{array}{c}1 \mathrm{~B} \\
0\end{array}$ & $\begin{array}{l}\mathbf{1 A} \\
\nabla\end{array}$ & $\begin{array}{l}\mathbf{1 B} \\
\nabla\end{array}$ \\
\hline $0.01-0.01$ & \multicolumn{2}{|c|}{$<|0.03|$} & \multicolumn{2}{|c|}{$<0.04 \mid$} & \multicolumn{2}{|c|}{$0.68 / \mathrm{AP}$} & \multicolumn{2}{|c|}{ AP } & \multicolumn{2}{|c|}{0.20} & \multicolumn{2}{|c|}{$<|0.065|$} & \multicolumn{2}{|c|}{$\mathrm{AP}$} \\
\hline $0.01-0.02$ & \multicolumn{2}{|c|}{$<|0.03|$} & \multicolumn{2}{|c|}{$<|0.04|$} & \multicolumn{2}{|c|}{$0.87 / \mathrm{AP}$} & \multicolumn{2}{|c|}{ AP } & \multicolumn{2}{|c|}{ AP } & \multicolumn{2}{|c|}{$<|0.065|$} & \multicolumn{2}{|c|}{ AP } \\
\hline $0.01-0.03$ & \multicolumn{2}{|c|}{$<|0.03|$} & \multicolumn{2}{|c|}{$<|0.04|$} & \multicolumn{2}{|c|}{$0.87 / 0.26$} & \multicolumn{2}{|c|}{ AP } & \multicolumn{2}{|c|}{ AP } & & & & \\
\hline $0.01-0.04$ & & & & & & & & & & & & & & \\
\hline $0.01-0.05$ & & & & & & & & & & & & & & \\
\hline $0.02-0.01$ & & & & & & & & & & & & & & \\
\hline $0.02-0.02$ & & & & & & & & & & & & & & \\
\hline $0.02-0.03$ & & & & & & & & & & & & & & \\
\hline $0.02-0.04$ & & & & & & & & & & & & & & \\
\hline $0.02-0.05$ & & & & & & & & & & & & & & \\
\hline $0.03-0.01$ & & & & & & & & & & & & & & \\
\hline $0.03-0.02$ & & & & & & & & & & & & & & \\
\hline $0.03-0.03$ & & & & & & & & & & & & & & \\
\hline $0.03-0.04$ & & & & & & & & & & & & & & \\
\hline $0.03-0.05$ & & & & & & & & & & & & & & \\
\hline $0.04-0.01$ & & & & & & & & & & & & & & \\
\hline $0.04-0.02$ & & & & & & & & & & & & & & \\
\hline $0.04-0.03$ & & & & & & & & & & & & & & \\
\hline $0.04-0.04$ & & & & & & & & & & & & & & \\
\hline $0.04-0.05$ & & & & & & & & & & & & & & \\
\hline $0.05-0.01$ & & & & & & & & & & & & & & \\
\hline $0.05-0.02$ & & & & & & & & & & & & & & \\
\hline $0.05-0.03$ & & & & & & & & & & & & & & \\
\hline $0.05-0.04$ & & & & & & & & & & & & & & \\
\hline $0.05-0.05$ & & & & & & & & & & & & & & \\
\hline
\end{tabular}

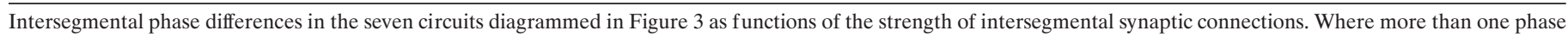

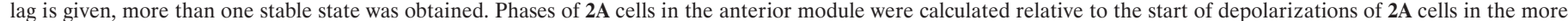

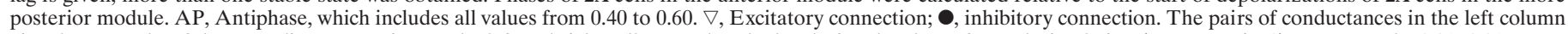

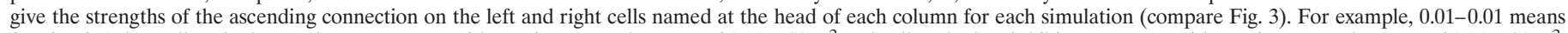

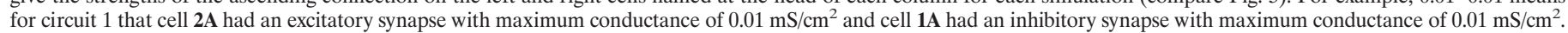

mediate phase lags could occur, and we found that none of the alternative patterns of descending connections with single cells in the target modules could by themselves produce appropriate lags throughout the same range of postsynaptic conductances. If we postulate two descending connections, then just as for the ascending coupling, there are seven possibilities to investigate. Like the ascending alternatives (Table 3 ), only three of the seven alternatives might be expected to produce intermediate phase lags. 


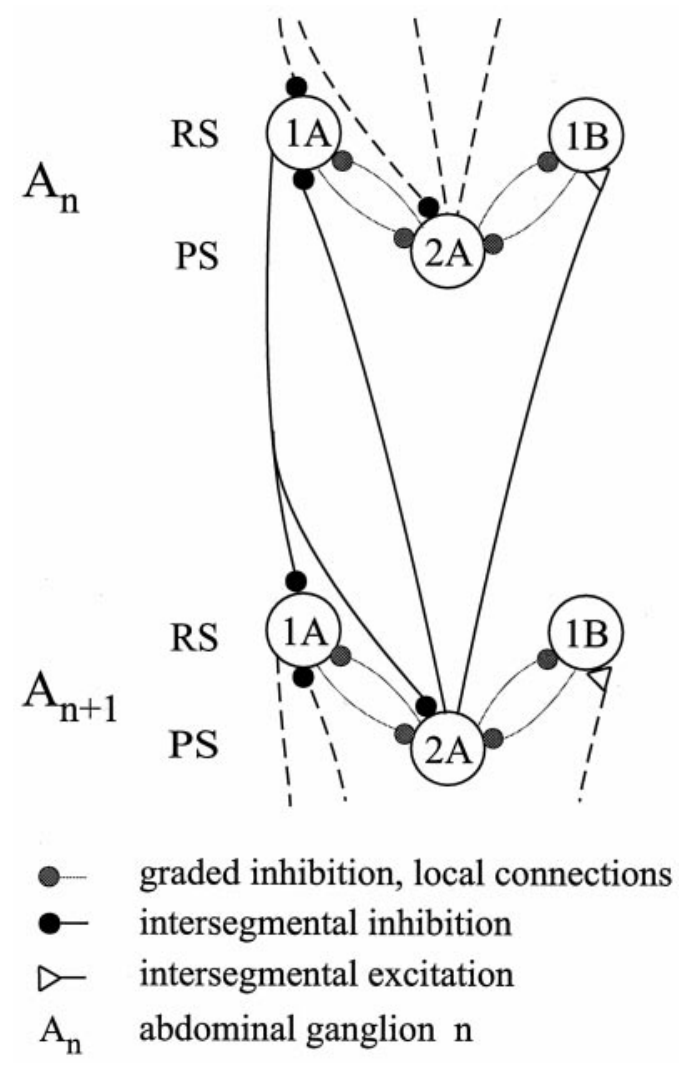

Figure 4. Diagram of the proposed model of the full intersegmental circuit that coordinates swimmerets in neighboring abdominal ganglia, $\mathrm{A}_{n}$ and $\mathrm{A}_{n+1}$. 1A, 1B, 2A, Individual nonspiking local cells within each module. The connections between modules are thought to be disynaptic; each coordinating interneuron is driven directly by a local interneuron in the module where it originates. Black circles, Intersegmental inhibitory chemical synapses; white triangles, intersegmental excitatory chemical synapses; gray circles, graded chemical inhibitory synapses.

Moreover, the PCO model predicts that ascending and descending coupling would be asymmetric, which eliminated the pattern of connections in ascending circuit 5, leaving us with two alternatives. We found that if the descending axon inhibited both $\mathbf{1 A}$ and $\mathbf{2 A}$ in the next posterior module (Table 4), the model circuit produced appropriate lags. No discrete PSPs have been recorded from 2A interneurons (Paul and Mulloney, 1985b).

\section{A cellular model of the intersegmental coordinating circuit}

This analysis of the dynamics of alternative ascending and descending patterns of connections leads us to propose a model of the intersegmental circuit that incorporates a minimal number of the known components of the system organized in a specific asymmetric pattern. For modules positioned in the interior of the series, the full coordinating circuit is illustrated in Figure 4; modules located at the anterior or posterior ends do not get input from the anterior or posterior direction, respectively. In this coordinating circuit, either ascending connections or descending connections alone can coordinate neighboring modules with a phase difference of $\sim 25 \%$.

\section{Modulating the period of the model}

To test the full model of four local modules connected by this circuit (Fig. 4), we first established a set of standard values for cellular and synaptic parameters (Table 4) that allowed the sys-

\begin{tabular}{|c|c|c|c|}
\hline Parameter & Value & Units & $\begin{array}{l}\text { Varied } \\
\text { (yes/no) }\end{array}$ \\
\hline$g_{\mathrm{Ca}}, g_{\mathrm{K}}, g_{\mathrm{L}}$ & $0.3,0.3,0.2$ & $\mathrm{mS} / \mathrm{cm}^{2}$ & Yes \\
\hline$V_{\mathrm{Ca}}, V_{\mathrm{K}}, V_{\mathrm{L}}$ & $100,-80,-60$ & $\mathrm{mV}$ & No \\
\hline$V_{\text {syn }}($ excite $), V_{\text {syn }}($ inhib $)$ & $0,-65$ & $\mathrm{mV}$ & No \\
\hline$C$ & 1 & $\mu \mathrm{F} / \mathrm{cm}^{2}$ & No \\
\hline$I_{\text {ext }}$ & 1 & $\mu \mathrm{A} / \mathrm{cm}^{2}$ & Yes \\
\hline$V_{\text {thresh }}$ & -50 & $\mathrm{mV}$ & Yes \\
\hline$V_{\text {slope }}$ & 10 & $\mathrm{mV}$ & No \\
\hline$g_{\text {syn }}(2 \mathrm{~A} \rightarrow 1 \mathrm{~A}, 1 \mathrm{~B})$ & 0.1 & $\mathrm{mS} / \mathrm{cm}^{2}$ & Yes \\
\hline$g_{\text {syn }}(1 \mathrm{~A}, 1 \mathrm{~B} \rightarrow 2 \mathrm{~A})$ & 0.05 & $\mathrm{mS} / \mathrm{cm}^{2}$ & Yes \\
\hline$\phi_{N}$ & 0.006 & $\mathrm{msec}^{-1}$ & Yes \\
\hline$V_{1}$ & -25 & $\mathrm{mV}$ & Yes \\
\hline$V_{2}$ & 20 & $\mathrm{mV}$ & Yes \\
\hline$V_{3}$ & -30 & $\mathrm{mV}$ & Yes \\
\hline$V_{4}$ & 15 & $\mathrm{mV}$ & Yes \\
\hline$\tau_{S}$ & 500 & msec & Yes \\
\hline$g_{\text {inter.syn }}(2 \mathrm{~A} \rightarrow 1 \mathrm{~A}$, asc $)$ & 0.03 & $\mathrm{mS} / \mathrm{cm}^{2}$ & Yes \\
\hline$g_{\text {inter.syn }}(2 \mathrm{~A} \rightarrow 1 \mathrm{~B}$, asc $)$ & 0.02 & $\mathrm{mS} / \mathrm{cm}^{2}$ & Yes \\
\hline$g_{\text {inter.syn }}(1 \mathrm{~A} \rightarrow 1 \mathrm{~A}$, desc $)$ & 0.03 & $\mathrm{mS} / \mathrm{cm}^{2}$ & Yes \\
\hline$g_{\text {inter.syn }}(1 \mathrm{~A} \rightarrow 2 \mathrm{~A}$, desc $)$ & 0.01 & $\mathrm{mS} / \mathrm{cm}^{2}$ & Yes \\
\hline SMT threshold & -30 & $\mathrm{mV}$ & No \\
\hline$\alpha$ & 4 & $\mathrm{msec}^{-1} \cdot \mathrm{mM}^{-1}$ & No \\
\hline$\beta$ & 2 & $\mathrm{msec}^{-1}$ & No \\
\hline$T$ & 1 & $\mathrm{~mm}$ & No \\
\hline Spike duration & 2.5 & msec & No \\
\hline Interspike interval & 10 & msec & No \\
\hline
\end{tabular}

tem to oscillate at $\sim 2 \mathrm{~Hz}$ with intersegmental phases in the range of $20-25 \%$, criteria that fall in the middle of the normal operating range of the swimmeret system (Mulloney et al., 1993). Next we investigated the effect on period of changing various parameters in the model (see Table 4). To do so, we examined an individual module to determine which parameters controlled the period of its oscillations and then extended this examination to the fully interconnected system of four modules. Systematically changing $V_{\text {thresh }}, \tau_{\mathrm{S}}, g_{\text {syn }}, g_{\text {inter.syn }} g_{\mathrm{Ca}}, g_{\mathrm{K}}, g_{\mathrm{L}}, V_{1}, V_{2}, V_{3}$, and $I_{\text {ext }}$ affected period, but either the range of possible periods was less than twofold, or relative duration and intersegmental phases were not preserved. However, we discovered that modulating the rate constant of outward currents, $\lambda_{\mathrm{N}}$, by changes in $\phi_{\mathrm{N}}$ or $V_{4}$ could cause more than a twofold change in period, and that the relative durations of depolarizations were preserved despite these changes (see Figs. $2 B, C$, for the solitary module, $6 B$ ), so we used changes in $\phi_{\mathrm{N}}$ to simulate changes in the level of excitation of the system (Mulloney, 1997). Hence, as predicted by the PCO model, we found that the frequency of coordinated oscillations of the system was determined largely by properties of its individual modules, not by properties of the intersegmental connections.

\section{Performance of the cellular model}

To assess the performance of this model, we varied the frequency of its oscillations from 1 to $3.2 \mathrm{~Hz}$ by altering the rate of activation of the outward current in individual cells (Fig. 2B) and compared the intersegmental phases and the relative durations of depolarizations of cells in each module with the intersegmental phases and durations of bursts in PSE and RSE motor neurons recorded from experimental preparations active at different frequencies.

In experimental preparations that expressed swimmeret motor 

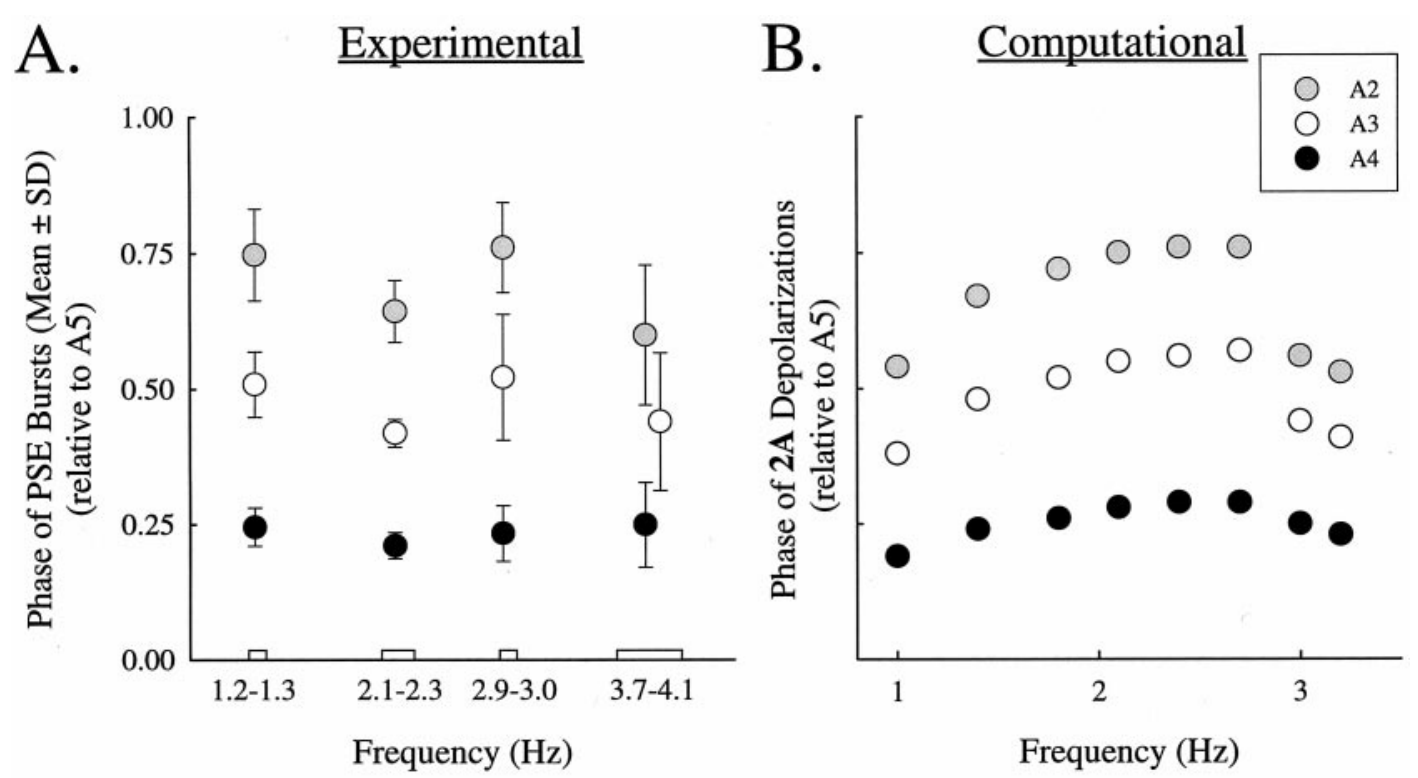

Figure 5. Comparison of intersegmental phases of PSE motor neurons measured in experimental preparations $(A)$ with phases of depolarizations of 2A cells computed in the model $(B)$. Mean phases of bursts of impulses recorded from PSE axons in A2, A3, A4, and A5 were calculated for four ranges of cycle frequencies. The plotted points are means of all experiments within that range. At the highest frequency, the experimental point for A3 is offset horizontally to make the error bars unambiguous. In the computational analysis, we calculated phases of periodic depolarizations of $2 \mathrm{~A}$ cells at different frequencies of oscillations. These frequencies were changed by modulating $\phi_{N}$ between 0.003 and $0.010 \mathrm{msec}^{-1}$.

patterns with different periods, intersegmental phases of bursts in PSE motor neurons showed some individual variation (Fig. 5A), but the mean values of the phase of each segment were independent of burst frequency. In these preparations (Mulloney, 1997), PSE bursts in A2, A3, A4, and A5 were recorded at different burst frequencies. In this figure, the mean phases of PSE bursts in A2, A3, and A4 relative to PSE bursts in A5 were calculated for four different ranges of burst frequencies, and the points plotted are means of all experiments within that range.

In our simulations, there were no components corresponding directly to PSE motor neurons, but we had assumed that bursts of impulses in PSE motor neurons were driven by $\mathbf{2 A}$ when these cells were depolarized (Fig. $2 A$ ), so we compared the phases of 2A depolarizations in different modules computed at different frequencies (Fig. $5 B$ ). The phases of $\mathbf{2 A}$ depolarizations in different modules, relative to depolarizations of $\mathbf{2 A}$ in A5, were similar to the phases of bursts of impulses in PSE motor neurons in different segments relative to bursts in PSE motor neurons in A5.

A distinctive feature of the normal motor output of the swimmeret system is that the relative durations of bursts of impulses in PSE and RSE motor neurons are preserved as the period of motor pattern changes. To accomplish this preservation, the durations of each burst decrease as period decreases (Braun and Mulloney, 1995). If this compensation were perfect, the relative duration of each burst would be constant despite changes in period. To compare the performance of the swimmeret system with the performance of the model, we calculated the mean relative durations of bursts of impulses in PSE motor neurons recorded in preparations expressing coordinated motor patterns with different cycle frequencies (Fig. 6A) and compared them with the relative durations of depolarizations of $\mathbf{2 A}$ cells computed in simulations with different cycle frequencies (Fig. 6B). At frequencies $<2.4 \mathrm{~Hz}$, the relative durations of the system and the model are not different. At higher frequencies, the computed relative durations of $\mathbf{2 A}$ are briefer than the measured relative durations in PSE motor neurons.

\section{Sensitivity of the model to synaptic parameters}

In this model, the kinetics of intersegmental synapses were much faster than those of the graded synapses between local cells within each module. This difference proved to be important if the model was to approximate both the phase differences and the relative durations of the real system. If local synaptic time constants were too slow, e.g., $1.0 \mathrm{sec}$, then intersegmental factors could dominate the behavior of the local module such that depolarizations of local cells were terminated prematurely by incoming inhibitory signals. If local synaptic time constants were too fast, e.g., $0.25 \mathrm{sec}$, then the behavior of the individual module quickly stabilized and prevented intersegmental signals from significantly affecting phase lags. We found that a time constant of $0.5 \mathrm{sec}$ for the graded local synapses gave an appropriate balance between local and intersegmental factors (Table 4). This balance of synaptic parameters might be linked to our observations (above) that changes in either $\phi_{\mathrm{N}}$ or $V_{4}$, both intrinsic properties of individual cells, changed the frequency of the system but preserved phases and relative durations. Previous modeling of reciprocal inhibitory circuits found that changes in intrinsic properties could cause either increases or decreases in the period of oscillations of the circuit, depending on the underlying mechanisms that drive these oscillations (Skinner et al., 1994; Sharp et al., 1996). These mechanisms could be "intrinsic" or "synaptic" (Skinner et al., 1994). Flexibility in the mechanism generating the oscillations of each module might be a way to preserve intersegmental phase and relative duration as frequency changes.

\section{Contributions of ascending connections and descending connections to the stability of the performance of the model}

Given that either the ascending connections or descending connections of the model alone could cause phase lags in the right range when the local circuits were oscillating at $\sim 2 \mathrm{~Hz}$, we examined how ascending and descending connections performed at different frequencies. We ran a series of simulations with either 


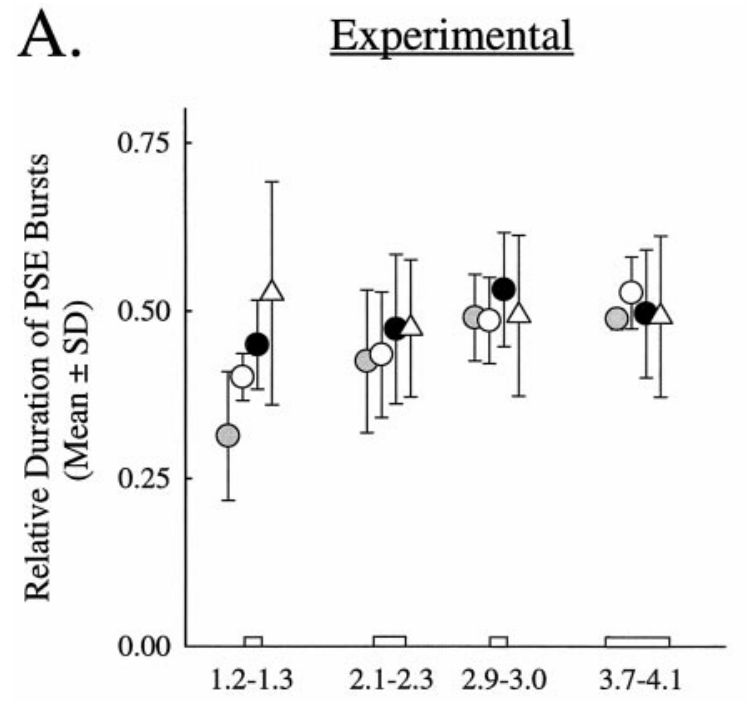

Frequency $(\mathrm{Hz})$
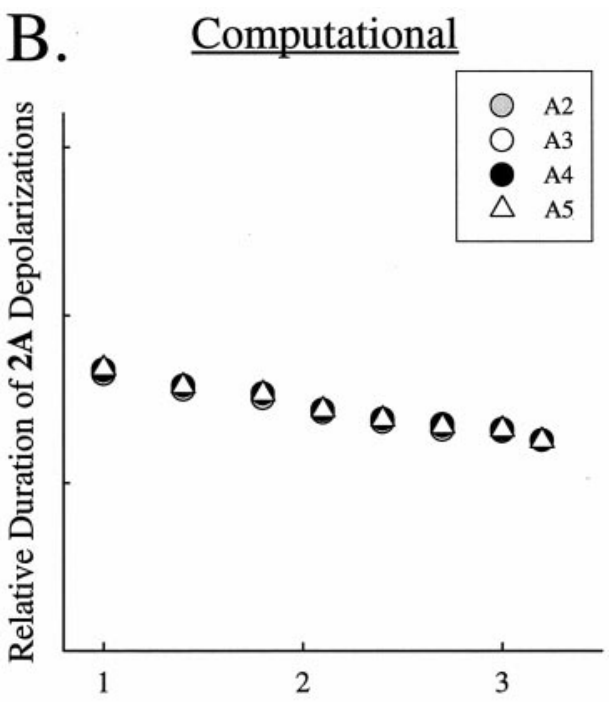

Frequency $(\mathrm{Hz})$

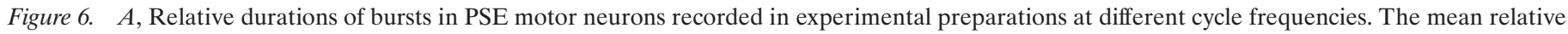

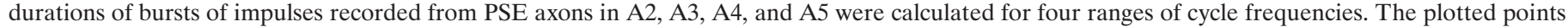

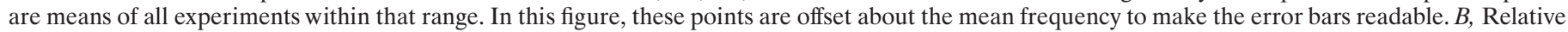
durations of depolarizations of $\mathbf{2 A}$ cells as functions of frequency. Frequency modulation was accomplished with the method described in Figure 5.

only ascending or only descending connections and different intrinsic cycle frequencies. Both the ascending-only and the descending-only circuits produced coordinated activity with substantial differences in intersegmental phase, posterior segments leading, at all frequencies tested (Fig. 7A). The performance of these circuits differed most at low frequencies; ascending-only output had small intersegmental phase differences, but descending-only output had larger phase differences. This suggests that the better performance of the full circuit (Fig. 5) results from balancing contributions of ascending and descending connections.

The relative durations of depolarizations of the three local cells in each module, in contrast to their intersegmental phases, were similar in the ascending-only and descending-only series (Fig. 7B) and similar to their relative durations computed with the full circuit (Fig. 6). Results from module A4 are plotted in Figure 7B; the relative durations of the homologous cells in other modules were similar to these.

Other simulations indicate that the full model, with both ascending and descending connections (Fig. 4), is more resilient to perturbation of these intersegmental synapses than is either the ascending-only or descending-only circuit. In particular, we found that the full circuit could maintain normal intersegmental coordination through a larger range of intersegmental synaptic strengths than could the ascending-only circuit. For smaller changes, both circuits maintained coordination.

\section{DISCUSSION}

Coordination of limb movements during normal locomotion is fundamental to behavior, but the mechanisms that achieve it are little understood. Although phasic sensory feedback is critical if these movements are to be adapted to local requirements and to accidents of individual histories (Wilson, 1968; Grillner, 1981), the CNSs of most animals are organized so that essential features of this coordination can be accomplished without any sensory input. The swimmeret system in crayfish illustrates this property particularly clearly (Hughes and Wiersma, 1960; Ikeda and Wiersma, 1964). We present a cellular model of the swimmeret coordinating circuit that is based on experimental results and predictions made by our PCO model of this system (Skinner et al., 1997) and that incorporates essential features of the architectonics of the system.

This model effectively reproduces key features of the performance of the swimmeret system: invariant intersegmental phases and relative durations of activity. Many of the alternative circuits that we simulated did not perform at all like the real system (Table 3), so it is remarkable that one alternative was so effective. Only when the four local modules were linked by this pattern of coordinating connections were both the intersegmental phases of their oscillations and the relative durations of depolarization of individual local cells preserved as the cycle frequency of the system changed (Figs. 5, 6). For the model to maintain normal intersegmental phase differences, the strengths of the ascending and descending signals had to be similar, and the time constants of local and intersegmental synaptic connections had to be balanced, but within these constraints, either ascending or descending axons connected in this way would cause an $\sim 25 \%$ phase difference (Fig. 7) with posterior leading. The model was constructed by assuming a reciprocal inhibitory organization of particular local interneurons (Fig. $2 A$ ) and by using experimental data (Tables 1,2$)$ to restrict the number and properties of intersegmental connections. Thus, this model illustrates how local interneurons and intersegmental interneurons could be organized in a particular configuration to coordinate swimmeret movements.

One widely applicable result of this study is how changes in excitation were modeled. Although the swimmeret system can be modulated by different putative transmitters (Mulloney et al., 1987; Sherff and Mulloney, 1991; Braun and Mulloney, 1993; Chrachri and Neil; 1993), and differential modulation of particular phases of the pattern is known (Mulloney et al., 1997), the 


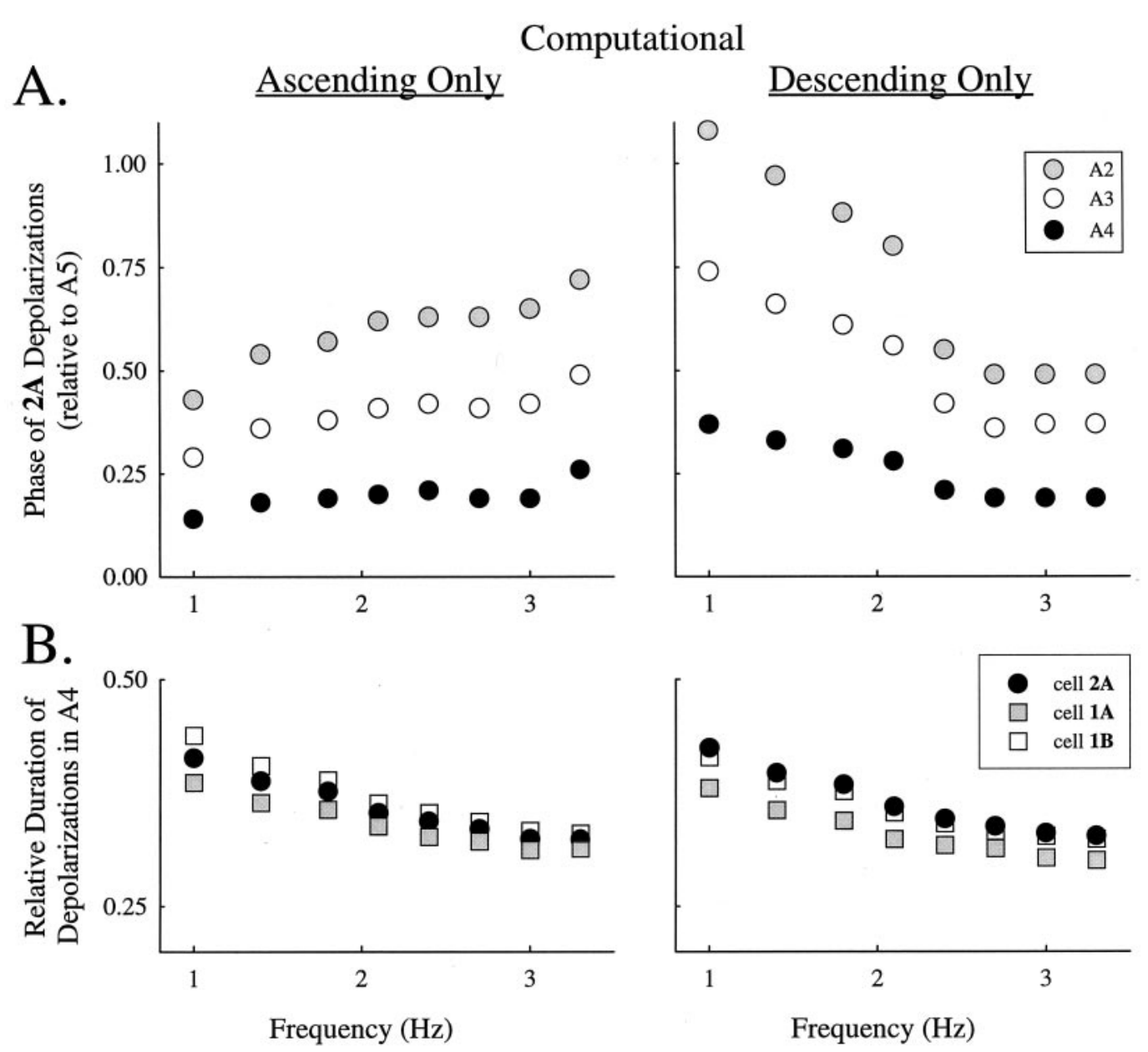

Figure 7. Features of the coordination of a four-module chain computed when only ascending connections or only descending connections of the proposed coordinating circuit (Fig. 4) were present. $A$, Phases of depolarizations of $\mathbf{2 A}$ cells in anterior modules as functions of cycle frequency. $B$, Relative durations of depolarizations of cells $\mathbf{1 A}, \mathbf{1 B}$, and $\mathbf{2 A}$ in module A4 computed at different frequencies. Frequency modulation was accomplished with the method described in Figure 5.

cellular mechanisms by which frequencies of periodic motor patterns change are largely unknown. While studying the dynamics of the model, we found it difficult to vary its frequency widely. One common tactic for changing firing frequencies of model neurons is to change injected current (Skinner et al., 1993). However, in this model, intersegmental coordination and relative durations were not maintained through a range of cycle frequencies if steady currents were injected into individual cells. Instead, relative durations increased as the frequency of oscillations increased, unlike the response of the swimmeret system to changes in excitation (Fig. 6). We tried varying other cellular parameters (Table 4), but only changing the kinetics of the outward current in Equation 1 allowed the circuit to match the performance of the system. Modulation of outward currents exerts substantial control over period and phase in other pattern-generating circuits (Marder and Calabrese, 1996), and despite the simplifications inherent in our simulations, our results suggest that modulation of potassium currents might be part of the mechanism by which the period of swimmeret beating is controlled.

\section{Simplifications inherent in these models}

The proposed model of the swimmeret coordinating circuit incorporates significant cellular details of the swimmeret system, but in simplified ways. Both the models of individual cells and of their local and intersegmental synapses are attempts to capture only their essential features. The model of each local patterngenerating circuit (Fig. $2 A$ ) is a minimal cellular model, and some of its details have not yet been examined either computationally or experimentally. In constructing the four local circuits that simulated the modules in four neighboring segments, we further simplified this proposed local circuit by including only the cells that represented the nonspiking local interneurons (Table 1) but omitting both sensory components and motor neurons. In particular, the omission of motor neurons and the assumption that depolarization of $\mathbf{2 A}$ is synonymous with firing of PSE motor neurons should be tested experimentally.

In the model of this coordinating circuit (Fig. 4), we included a minimal set of elements that simulate the known coordinating interneurons (Table 2). The method used simplified these interneurons extremely; they played no role in their home segment; their firing frequencies were fixed and did not change when the frequencies of the local circuits that drove them changed. In physiological experiments, coordinating interneurons do respond to changing levels of excitation (H. Namba and B. Mulloney, unpublished results). Preliminary simulations in which their spike frequencies increased uniformly as excitation increased gave intersegmental phases and relative durations in the same ranges as 
those reported here. These simplifications might cause the imperfect correspondence between model and experiment, especially at the higher frequencies. This feature may become more important when we consider nonuniform excitation (Braun and Mulloney, 1995).

\section{Relation of the PCO model to this model}

It is productive to consider a complex system from different perspectives but sometimes difficult to map the results of different levels of consideration. In an earlier study (Skinner et al., 1997), we considered only the phase differences between segments and asked what properties of coordinating information linking neighboring segments were necessary to produce phase-differences of $25 \%$. Predictions from that study, that either ascending coupling or descending coupling alone would produce the appropriate phase difference and that ascending and descending coupling were asymmetric, suggested the strategy that let us sort efficiently through different circuits that interneurons might make (Fig. 3). PCO models as a class, because they include only phase and coupling as parameters, are limited in the extent to which they can illuminate the mechanisms that determine the performance of the system. They may predict asymmetry but are silent on the nature of that asymmetry (Pearce and Friesen, 1988; Williams, 1992b; Sigvardt, 1993). This cellular model, in contrast, illustrates how a coordinating circuit can be asymmetric yet equally effective in ascending and descending directions. The "coupling" between modules is asymmetric in that the targets of ascending connections are different from the targets of descending connections and also in that the signals these targets received are not the same sign.

\section{Comparison of this model with similar models of circuits coordinating locomotion in other animals}

The spinal control of swimming in leeches, lamprey, and tadpoles has also been simulated with cellular models of segmental oscillators (Williams, 1992a; Grillner et al., 1995; Roberts et al., 1995; Jung et al., 1996). The complexity of neuronal properties included in these models differs widely; our descriptions of the nonspiking local neurons in each module included voltage-gated currents and graded postsynaptic currents integrated in a single compartment and so are of intermediate complexity. A detailed model of the segmental and intersegmental circuits that control swimming in leeches has been developed and refined by interaction of simulation and experiment (Friesen, 1989; Friesen and Pearce, 1993). This model differs from the one presented here in that its connections are justified by physiological recordings, and that the contributions of cellular dynamics to the performance of the circuit have not yet been investigated (cf. Canavier et al., 1997).

Walking in terrestrial vertebrates is driven by spinal pattern generators, one for each limb, or perhaps one for each joint in the limb, that are coordinated by interneurons in the spinal cord (Rossignol et al., 1993; Berkowitz and Stein, 1994). The properties of motor neurons and their modulators (Kiehn et al., 1997) and the contributions of segmental circuits to limb movements (Stein et al., 1995) have been described, but no cellular model of these coordinating circuits has been proposed. Walking in insects and crustaceans involves more pairs of limbs, but smaller numbers of neurons, than it does in vertebrates. Each walking leg has its own module (Ronacher, 1991). The cellular organization of reflexes in the walking legs (Burrows, 1992; Wolf and Laurent, 1994) and properties of intersegmental interneurons that might coordinate legs during walking have been well characterized
(Laurent, 1988; Laurent and Burrows, 1989a,b). Cholinergic reagents elicit coordinated stepping motor patterns from isolated thoracic ganglia of locusts (Ryckebusch and Laurent, 1994) and crayfish (Chrachri and Clarac, 1990), but the coordination of the pattern generators for walking in these isolated ganglia has proven more variable than those produced by the isolated swimmeret system (Sillar et al., 1987; Ryckebusch and Laurent, 1994; Berkowitz and Laurent, 1996a,b), and the models of the coordinating circuit for walking that have been proposed are still quite abstract (Müller and Cruse, 1991; Beer et al., 1992; Ryckebusch et al., 1994).

Our results suggest specific features both of the structure of each module and of the intersegmental coordinating circuit. Given the assumption that the core of each module is the reciprocal inhibitory connections made by specific nonspiking local interneurons (Fig. $2 A$ ), they predict that neighboring modules are linked by a specific configuration of intersegmental connections (Fig. 4). The model illustrates that coordinating interneurons do not need to affect pattern-generating neurons in their home modules directly; instead, their axons conduct impulses to particular targets in neighboring modules. Many of these details are in principle testable by physiological experiment.

\section{REFERENCES}

Beer RD, Chiel HJ, Quinn RD, Espenschied KS, Larsson P (1992) A distributed neural network architecture for hexapod robot locomotion. Neural Comput 4:356-365.

Berkowitz A, Laurent G (1996a) Local control of leg movements and motor patterns during grooming in locusts. J Neurosci 24:8067-8078.

Berkowitz A, Laurent G (1996b) Central generation of grooming motor patterns and interlimb coordination in locusts. J Neurosci 24:8079-8091.

Berkowitz A, Stein PSG (1994) Activity of descending propriospinal axons in the turtle hindlimb enlargement during two forms of fictive scratching: broad tuning to regions of the body surface. J Neurosci 14:5089-5104.

Braun G, Mulloney B (1993) Cholinergic modulation of the swimmeret system in crayfish. J Neurophysiol 70:2391-2398.

Braun G, Mulloney B (1995) Coordination in the crayfish swimmeret system: differential excitation causes changes in intersegmental phase. J Neurophysiol 73:880-885.

Burrows M (1992) Local circuits for the control of leg movements in an insect. Trends Neurosci 15:226-232.

Canavier CC, Butera RJ, Dror RO, Baxter DA, Clark JW, Byrne JH (1997) Phase response characteristics of model neurons determine which patterns are expressed in a ring circuit model of gait generation. Biol Cybern 74:367-380.

Chrachri A, Clarac F (1990) Fictive locomotion in the fourth thoracic ganglion of the crayfish. J Neurosci 10:707-719.

Chrachri A, Neil DM (1993) Interaction and synchronization between two abdominal motor systems in crayfish. J Neurophysiol 69:1373-1383.

Destexhe A, Mainen ZF, Sejnowski TJ (1994) An efficient method for computing synaptic conductances based on a kinetic model of receptor binding. Neural Comput 6:14-18.

Edwards DH, Mulloney B (1984) Compartmental models of electrotonic structure and synaptic integration in an identified neurone. J Physiol (Lond) 348:89-113.

Edwards DH, Mulloney B (1987) Synaptic integration in excitatory and inhibitory crayfish motoneurons. J Neurophysiol 57:1425-1445.

Friesen WO (1989) Neuronal control of leech swimming movements. In: Neuronal and cellular oscillators (Jacklet JW, ed), pp 269-316. New York: Dekker.

Friesen WO, Pearce RA (1993) Mechanisms of intersegmental coordination in leech locomotion. Semin Neurosci 5:41-47.

Grillner S (1981) Control of locomotion in bipeds, tetrapods and fish. In: Handbook of physiology, the nervous system, Vol 2, Motor control (Brooks VB, ed), pp 1179-1236. Baltimore: Williams \& Wilkens.

Grillner S, Deliagina T, Ekeberg Ö, El Manira A, Hill RH, Lansner A, Orlovsky GN, Wallén P (1995) Neural networks that co-ordinate lo- 
comotion and body orientation in lamprey. Trends Neurosci 18:270-279.

Heitler WJ, Pearson KG (1980) Non-spiking interactions and local interneurones in the central pattern generator of the crayfish swimmeret system. Brain Res 187:206-211.

Hindmarsh AC (1983) Odepack, a systematized collection of ode solvers. In: Scientific computing (Stepleman RS, et al. eds), pp 55-64. Amsterdam: North-Holland.

Hughes GM, Wiersma CAG (1960) The co-ordination of swimmeret movements in the crayfish, Procambarus clarkii. J Exp Biol 37:657-670.

Ikeda K, Wiersma CAG (1964) Autogenic rhythmicity in the abdominal ganglion of the crayfish: the control of swimmeret movements. Comp Biochem Physiol 12:107-115.

Jung R, Kiemel T, Cohen AH (1996) Dynamic behavior of a neural network model of locomotor control in the lamprey. J Neurophysiol 75:1074-1086.

Kiehn O, Hounsgaard J, Sillar KT (1997) Basic building blocks of vertebrate spinal central pattern generators. In: Neurons, networks, and motor behavior (Stein PSG, Grillner S, Selverston AI, Stuart DG, eds), pp 47-59. Cambridge, MA: MIT.

Killian KA, Page CH (1992a) Mechanosensory afferents innervating the swimmerets of the lobster. I. Afferents activated by cuticular deformation. J Comp Physiol [A] 170:491-500.

Killian KA, Page CH (1992b) Mechanosensory afferents innervating the swimmerets of the lobster. II. Afferents activated by hair deflection. J Comp Physiol [A] 170:501-508.

Laurent G (1988) Local circuits underlying excitation and inhibition of intersegmental interneurons in the locust. J Comp Physiol [A] 162:145-158.

Laurent G, Burrows M (1989a) Intersegmental interneurons can control the gain of reflexes in adjacent segments of the locust by their action on nonspiking local interneurons. J Neurosci 9:3030-3039.

Laurent G, Burrows M (1989b) Distribution of intersegmental inputs to nonspiking local interneurons and motor neurons in the locust. J Neurosci 9:3019-3029.

Marder E, Calabrese R (1996) Principles of rhythmic motor pattern generation. Physiol Rev 76:687-717.

Morris C, Lecar H (1981) Voltage oscillations in the barnacle giant muscle fiber. Biophys J 35:193-213.

Müller U, Cruse H (1991) The contralateral coordination of walking legs in the crayfish Astacus leptodactylus. II. Model calculations. Biol Cybern 64:437-446.

Mulloney B (1997) A test of the excitability-gradient hypothesis in the swimmeret system of crayfish. J Neurosci 17:1860-1868.

Mulloney B, Hall WM (1987) The PD programs: a method for the quantitative description of motor patterns. J Neurosci Methods 19:47-59.

Mulloney B, Perkel DH (1988) The roles of synthetic models in the study of central pattern generators. In: Neural control of rhythmic movements in vertebrates (Cohen AH, Rossignol S, Grillner S, eds), pp 415-453. New York: Wiley.

Mulloney B, Acevedo LD, Bradbury AG (1987) Modulation of the crayfish swimmeret rhythm by octopamine and the neuropeptide proctolin. J Neurophysiol 58:584-597.

Mulloney B, Murchison D, Chrachri A (1993) Modular organization of pattern-generating circuits in a segmental motor system: the swimmerets of crayfish. Semin Neurosci 5:49-57.

Mulloney B, Namba H, Agricola H-J, Hall WM (1997) Modulation of force during locomotion: differential action of crustacean cardioactive peptide on power-stroke and return-stroke motor neurons. J Neurosci 17:6872-6883.

Murchison D, Chrachri A, Mulloney B (1993) A separate local patterngenerating circuit controls the movements of each swimmeret in crayfish. J Neurophysiol 70:2620-2631.

Paul DH, Mulloney B (1985a) Local interneurons in the swimmeret system of the crayfish. J Comp Physiol [A] 156:489-502.

Paul DH, Mulloney B (1985b) Nonspiking local interneuron in the motor pattern generator for the crayfish swimmeret. J Neurophysiol 54:28-39.

Paul DH, Mulloney B (1986) Intersegmental coordination of swimmeret rhythms in isolated nerve cords of crayfish. J Comp Physiol [A] 158:215-224.
Pearce RA, Friesen WO (1988) A model for intersegmental coordination in the leech nerve cord. Biol Cybern 58:301-311.

Perkel DH, Mulloney B (1978) Electrotonic properties of neurons: steady-state compartmental model. J Neurophysiol 41:621-639.

Roberts A, Tunstall MJ, Wolf E (1995) Properties of networks controlling locomotion and significance of voltage dependency of NMDA channels: simulation study of rhythm generation sustained by positive feedback. J Neurophysiol 73:485-495.

Ronacher B (1991) Contribution of abdominal commissures in the bilateral coordination of the hindlegs during stridulation in the grasshopper Chorthippus dorsatus. J Comp Physiol [A] 169:191-200.

Rossignol S, Saltiel P, Perreault M-C, Drew T, Pearson KG, Belanger M (1993) Intralimb and interlimb coordination in the cat during real and fictive rhythmic motor patterns. Semin Neurosci 5:67-75.

Ryckebusch S, Laurent G (1994) Interactions between segmental leg central pattern generators during fictive rhythms in the locust. J Neurophysiol 72:2771-2785.

Ryckebusch S, Wehr M, Laurent G (1994) Distinctive rhythmic locomotor patterns can be generated by a simple adaptive neural circuit: biology, simulation, and VLSI implementation. J Comput Neurosci 1:339-358.

Sharp AA, Skinner FK, Marder E (1996) Mechanisms of oscillation in dynamic clamp constructed two-cell half-center circuits. J Neurophysiol 76:867-883.

Sherff CM, Mulloney B (1991) Red pigment concentrating hormone is a modulator of the crayfish swimmeret system. J Exp Biol 155:21-35.

Sherff CM, Mulloney B (1996) Tests of the motor neuron model of the local pattern-generating circuits in the swimmeret system. J Neurosci 16:2839-2859.

Sherff CM, Mulloney B (1997) Passive properties of swimmeret motor neurons. J Neurophysiol 78:92-102.

Sigvardt KA (1993) Intersegmental coordination in the lamprey central pattern generator for locomotion. Semin Neurosci 5:3-16.

Sillar KT, Clarac F, Bush BMH (1987) Intersegmental coordination of central neural oscillators for rhythmic movements of the walking legs in crayfish, Pacifastacus leniusculus. J Exp Biol 131:245-264.

Skinner FK, Turrigiano GG, Marder E (1993) Frequency and burst duration in oscillating neurons and two-cell networks. Biol Cybern 69:375-383.

Skinner FK, Kopell N, Marder E (1994) Mechanisms for oscillation and frequency control in reciprocally inhibitory model neural networks. J Comput Neurosci 1:69-88.

Skinner FK, Kopell N, Mulloney B (1997) How does the crayfish swimmeret system work? Insights from nearest neighbor coupled oscillator models. J Comput Neurosci 4:151-160.

Skinner K (1985) The structure of the fourth abdominal ganglion of the crayfish, Procambarus clarkii II. Synaptic neuropils. J Comp Neurol 234:182-191.

Stein PSG (1969) A neurophysiological study of two systems of coupled oscillators in crayfish. PhD thesis, Stanford University.

Stein PSG (1971) Intersegmental coordination of swimmeret motor neuron activity in crayfish. J Neurophysiol 34:310-318.

Stein PSG, Victor JC, Field EC, Currie SN (1995) Bilateral control of hindlimb scratching in the spinal turtle: contralateral spinal circuitry contributes to the normal ipsilateral motor pattern of fictive rostral scratching. J Neurosci 15:4343-4355.

Wiersma CAG, Hughes GM (1961) On the functional anatomy of neuronal units in the abdominal cord of the crayfish, Procambarus clarkii. J Comp Neurol 116:209-228.

Williams TL (1992a) Phase coupling by synaptic spread in chains of coupled neuronal oscillators. Science 662:662-665.

Williams TL (1992b) Phase coupling in simulated chains of coupled oscillators representing the lamprey spinal cord. Neural Comput 4:546-558.

Wilson DM (1968) Inherent asymmetry and reflex modulation of the locust flight motor pattern. J Exp Biol 48:631-641.

Wolf H, Laurent G (1994) Rhythmic modulation of the responsiveness of locust sensory local interneurons by walking pattern generating networks. J Neurophysiol 71:110-118. 